\title{
Skin reconstruction of the temporo parotid region
}

\begin{abstract}
Objectives: To determine the result of reconstruction with local or regional flaps of skin defects in the temporo-parotid region, after resection of malignant parotid gland and ear tumors, and to establish a reconstruction algorithm according to the size of the defect.

Methods: The electronic medical records of the patients who underwent surgery for malignant tumors of the parotid gland and ear with invasion of the skin of the region, and who had reconstructions of the skin defect with local and regional flaps, were selected. The surgeries were performed by the surgical team of the Otorhinolaryngology service of the Italian hospital in Buenos Aires between 2005 and 2018.

Results: Five patients were included.There were two malignant parotid gland tumors with histology of adenoid cystic carcinoma and squamous cell carcinoma, and three temporal bone tumors: squamous cell carcinoma, basal cell carcinoma in another and adenoid cystic carcinoma. The reconstructions were made with local or regional flaps. In skin defects smaller than $8 \mathrm{~cm}$ the reconstructions were made with cervical and scalp flaps. In skin defects larger than $8 \mathrm{~cm}$ the pectoralis major musculoctaneous flap were used. No patient had partial or total necrosis of the flaps.

Conclusions: The results of the reconstructions with local and regional flaps of the skin defects caused by the resection of malignant tumors of the ear and the parotid gland were very good, since they allowed the repair of the defect with a good aesthetic result, without the need to perform grafts in the donor area and with few minor complications. In patients with advanced malignant tumors of the ear and parotid gland with infiltration of the surrounding skin, it is better to do the reconstruction with local or regional flaps due to the greater simplicity and speed of the surgical technique, similar aesthetic results and few complications.
\end{abstract}

Keywords: temporo, parotíd, reconstruction, flap
Volume 12 Issue 4 - 2020

\author{
Ivo Bedini, Lautaro Acosta, Luciano Cavalieri, \\ Carlos Santiago Ruggeri \\ Head and Neck Section, Hospital of Buenos Aires, Argentina
}

Correspondence: Head and Neck Section, Hospital of Buenos Aires, Perón 4190, Ciudad Autónoma de Buenos Aires, Argentina, Email carlos.ruggri@hospitalitaliano.org.ar

Received: July 21, 2020 | Published: August 12, 2020

\section{Introduction}

Malignant tumors of the temporal bone and parotid gland that infiltrate the surrounding skin have a poor prognosis. The extension of the tumor to the skin in salivary gland cancer is staged as T4-A, and the extension to soft tissues greater than $0.5 \mathrm{~cm}$ in temporalbone cancer according to the staging of the University of Pittsburgh is considered T4. In soft tissue reconstruction, this prognosis should be considered and repairs should be indicated that reduce the time of surgery, cause little morbidity and are aesthetically similar to other more complex techniques. The use of local and regional flaps meet all the conditions described above, and are often the best option to repair soft tissue defects caused by surgery.

\section{Objectives}

To determine the result of reconstruction with local or regional flaps of skin defects in the temporo-parotid region, after resection of malignant parotid gland and ear tumors, and to establish a reconstruction algorithm according to the size of the defect.

\section{Design}

Descriptive and retrospective.

\section{Methods}

The electronic medical records of the patients who underwent surgery for malignant tumors of the parotid gland and ear with invasion of the skin of the region, and who had reconstructions of the skin defect with local and regional flaps, were selected. The surgeries were performed by the surgical team of the Otorhinolaryngology service of the Italian hospital in Buenos Aires between 2005 and 2018. Patients with malignant temporal and parotid gland tumors that had no skin invasion were excluded, as well as those with only partial resection of the pinna. Pre and postoperative facial nerve function was assessed using the House-Brackman scale. The patients were evaluated by computed tomography of the neck, neck and temporal bone, and with contrast magnetic resonance imaging. Four were studied with computed tomography of the chest, abdomen and pelvis and another with PET-CT to rule out disease at a distance. The following data were recorded in a table of type Excell 2010: age, sex, primary origin of the tumor, histology, type of surgery, previous treatments, size of the skin defect, reconstruction performed, and complications. It was called lateral temporalectomy when the lateral structures to the facial nerve (external auditory canal, tympanic membrane, hammer and incus) were resected, subtotal when all the anterior structures plus the labyrinth and cochlea were removed, and total when the internal auditory canal was also resected(petrosectomy). Temporalectomies were performed in conjunction with the otology team, and reconstructions were performed at the same surgical time. The facial nerve monitor (Nim Response Medtronic) was used in all surgeries. Small or medium skin defects were considered to be those that were less than $8 \mathrm{~cm}$ and large when they were greater than $>8 \mathrm{~cm}$.

\section{Results}

Five patients were included, three men and two women, the youngest being 46 and the oldest 86 years old. The average age was 67.8 years. Two patients with parotid gland malignancies consulted for the presence of the tumor and skin infiltration of the region, and the other three with temporal bone lesions for the presence of tumor 
in the external auditory canal, suppuration and skin infiltration of the temporal region. Only one of them had preoperative peripheral facial paralysis. Cervical metastases were detected in two, and none had distal metastases. The histological diagnosis of parotid gland tumors was adenoid cystic carcinoma and squamous cell carcinoma, and in temporal bone tumors: squamous cell carcinoma in one, basal cell carcinoma in another and adenoid cystic carcinoma.

Two had a history of previous radiation therapy. In parotid gland tumors, surgery consisted in: extended total parotidectomy with resection of the masseter muscle, partial removal of the pinna and skin with preservation of the facial nerve and modified radical neck dissection (N1). In another, a total parotidectomy was performed with resection of the facial nerve, and a partial excision of the pinna and the skin of the region. In two patients with ear tumors a lateral temporalectomy was performed and in another a subtotal. Two also had a superficial parotidectomy and another a total. In all, the pinna and skin of the region were resected. In one, a radical neck dissection(N2) was added. The reconstructions were made with local or regional flaps. In one patient with a skin defect of $7 \mathrm{~cm} \times 3.5 \mathrm{~cm}$, an anterior cervical flap was used, in two others with defects of $8 \mathrm{~cm}$ x $6 \mathrm{~cm}$ and $8 \mathrm{~cm} \times 7 \mathrm{~cm}$, rotating scalp flaps were made. Figures 1-3.

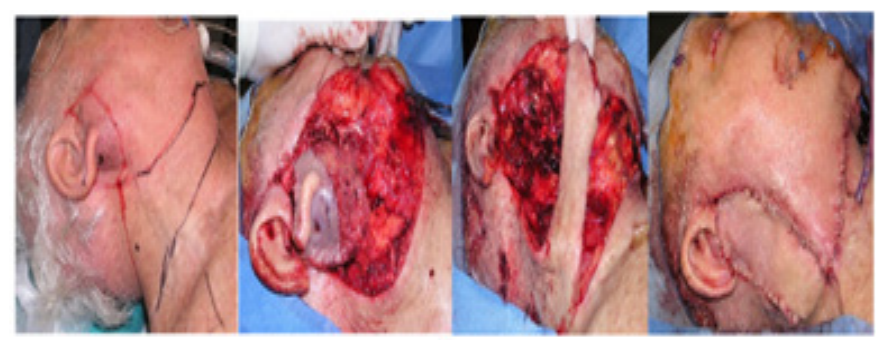

Figure I Anterior cervical flap.

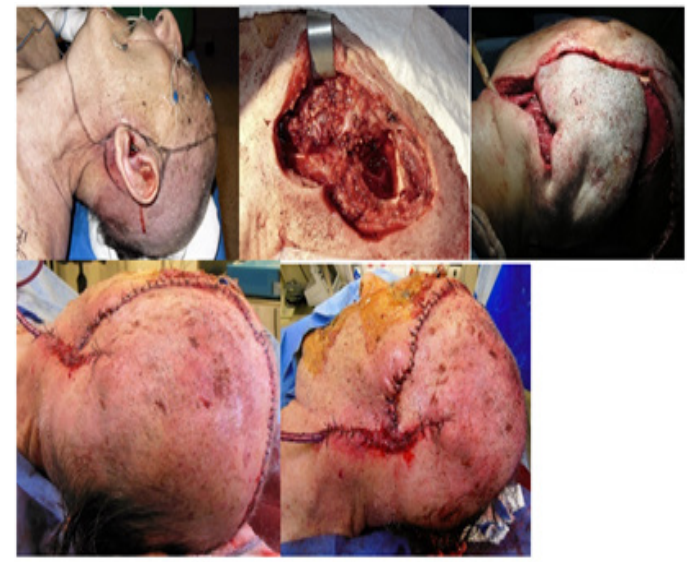

Figure 2 Occipital flap reconstruction.

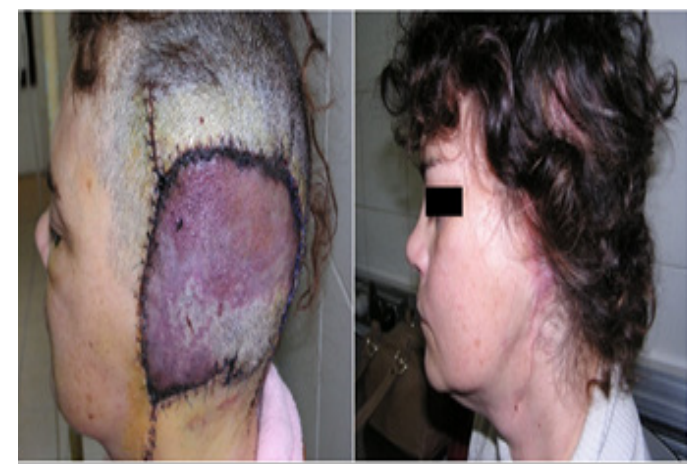

Figure 3 Occipital flap reconstruction: venous drainage alteration.
None of the three required a skin graft to cover the area exposed by the flap rotation. In larger skin defects $(11 \mathrm{~cm} \times 9 \mathrm{~cm}$, and $10 \mathrm{~cm} \times 9 \mathrm{~cm})$, a pectoralis major flap was used Figures $4 \& 5$. No patient had partial or total necrosis of the flaps, only one of the scalp used in a previously irradiated patient presented an alteration in the venous return with temporal cyanosis. The flap persisted vital and in approximately 21 days it acquired a normal coloration. In one of the patients in whom a pectoralis major flap was used, a small dehiscence occurred in the upper sector of the reconstruction that healed without the need for surgery. In the four patients without preoperative facial paralysis, the nerve function after surgery (evaluation at 30 days) was very good: Brackmann II in two and I in the other two (Table 1).
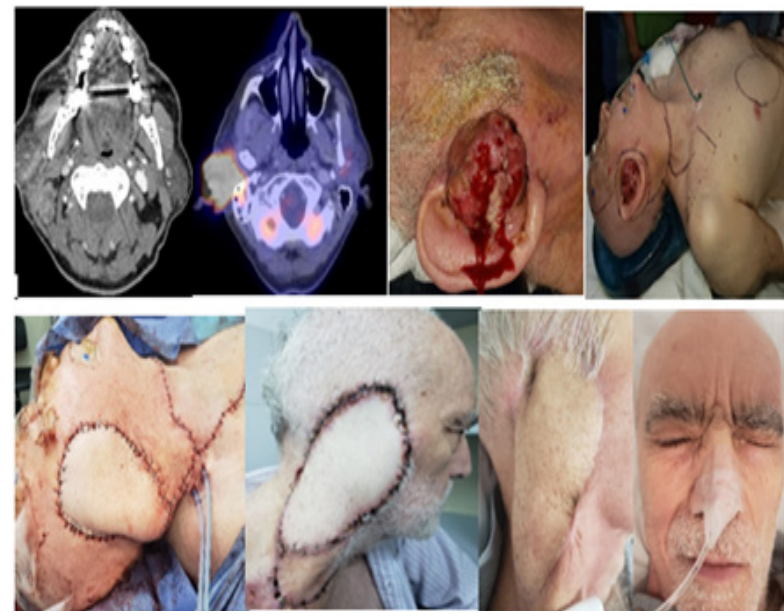

Figure 4 Pectoralis major flap reconstruction Postoperative facial nerve function: Brackmann I.

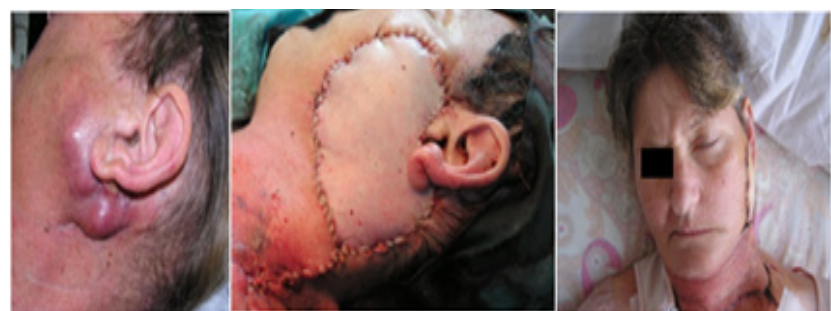

Figure 5 Musculocutaneous pectoralis major flap. Brackmann II (2I days postoperative).

\section{Discussion}

Malignant tumors of the parotid gland and temporal bone that compromise the skin of the region represent neoplasms with an advanced local stage, and therefore with a poor prognosis. In two studies of patients with ear tumors treated by temporalectomy, they reported a 3 -year disease-free survival rate of $38 \%{ }^{1}$ and an overall 5 -year survival of $31 \% .{ }^{2}$ Surgery is the best treatment given the location and the most common histologies of these tumors. Reconstruction of the defect created by resection of the pinna and surrounding skin is challenging since different types of flaps can be used and there is no consensus on which would be the best option. The type of reconstruction (mobilization of local tissues, transfer of adjacent head and neck sites or distant sites such as free flaps) will depend on the size of the defect, the patient's comorbidities, previous treatments, and the viability of the vascular pedicles that supply the flaps or representing the site for performing the microanastomosis. We also believe that the reduction of surgical time due to the choice of simple reconstructive techniques, and that have aesthetic results similar to other more complex ones, should be the first choice, especially in 
these patients with tumors with a poor prognosis. In one study they reported that a history of previous radiation therapy, more than 10 hours of anesthesia, and a high rate of comorbidities were associated with a greater number of peri and postoperative complications. Advanced age (>70years) and the highest number of comorbidities were associated with a greater severity of complications. ${ }^{3}$ Serletti reported that patients with an ASA III or IV classification had a high rate of medical, non-surgical complications after reconstruction with free flaps. When the elevated ASA was associated with a surgery time greater than 10 hours, there was an increase in surgical complications. In our study, ${ }^{3,4}$ patients were over 70years old, one also had an ASA IV anesthetic risk, and two antecedents of previous treatment with radiotherapy. The most commonly used local flaps to reconstruct the temporal-parotid region are those of the scalp. The irrigation comes from the superficial temporal artery and the occipital artery. The superficial temporal artery is usually sacrificed on resection.

Table I Patients treated and type of reconstruction us Surg, surgery

\begin{tabular}{|c|c|c|c|c|c|c|c|c|}
\hline Sex & Age & Location & Histology & $\begin{array}{l}\text { Previous } \\
\text { Treatment. }\end{array}$ & Surgery & SizeDefect & Reconstruction. & Complications \\
\hline$M$ & 86 & Parotid & $\begin{array}{l}\text { Squamouscell } \\
\text { carcinoma }\end{array}$ & not & Totalparotidectomy & $7 \times 3,5 \mathrm{~cm}$ & $\begin{array}{l}\text { Anterior } \\
\text { cervicalflap }\end{array}$ & not \\
\hline $\mathrm{F}$ & 54 & Parotid & $\begin{array}{l}\text { AdenoidCystic } \\
\text { Carcinoma }\end{array}$ & not & Totalparotidectomy & $10 \times 9 \mathrm{~cm}$ & Pectoralismajor & not \\
\hline$M$ & 77 & Ear & $\begin{array}{l}\text { Basal Cell } \\
\text { Carcinoma }\end{array}$ & $\mathrm{Rt}$ & LT & $8 \times 6 \mathrm{~cm}$ & Scalp & not \\
\hline$M$ & 76 & Ear & $\begin{array}{l}\text { Squamouscell } \\
\text { carcinoma }\end{array}$ & not & LT & $11 \times 9 \mathrm{~cm}$ & Pectoralismajor & Superior Dehiscence \\
\hline $\mathrm{F}$ & 46 & Ear & $\begin{array}{l}\text { AdenoidCystic } \\
\text { Carcinoma }\end{array}$ & Surg+ Rt & Subt $T$ & $8 \times 7 \mathrm{~cm}$ & Scalp & TransientVenousStasis \\
\hline
\end{tabular}

Rt, radioterapy; LT, lateral temporalectomy; Subt T, subtotal temporalectomy

Patients with a previous radiotherapy history, or those who underwent a neck dissection at the same surgical time (resection especially of lymph node groups II-IIb), may have alterations in flap viability, although the occipital artery has been preserved. Although it is also possible that if the fasciocutaneous flap was well designed it will survive by random vascular irrigation. ${ }^{5}$ In our study, we used the rotary flap of the scalp in two patients who had a history of previous radiation therapy (basal cell and adenoid cystic carcinoma), but in none neck dissection was done. We included the contralateral occipital pedicle in the flap dissection. It is our impression that the rotating scalp flap allows small or medium defects (not> $8 \mathrm{~cm}$ ) to be reconstructed without the need for grafts in the donor area. Other fasciocutaneous flaps have been described to reconstruct the temporoparotid region. The fascio or myocutaneous submental flap with the submental artery and vein as pedicles, ${ }^{6}$ the supraclavicular fasciocutaneous flap with a pedicle in the supraclavicular artery and vein, ${ }^{7}$ or the cervical flaps can be used. It is not advisable to use the first two flaps mentioned above if a neck dissection is performed, since although involvement of lymph node groups I and IV is unlikely in parotid or temporal bone tumors, dissection can jeopardize their vitality.

In an 86-year-old patient in our series, with high comorbidity (ASA IV), and with a small skin defect $(7 \mathrm{~cm} \times 3.5 \mathrm{~cm})$, we successfully used an anterior cervical flap, with random irrigation, for reconstruction. The other options for reconstruction of the temporoparotid region are the pediculated posterior trapezius and pectoralis major myocutaneous flaps. These are thicker and can better fill the temporalectomy defect.
The posterior trapezius flap has the disadvantage that its main pedicle, the posterior scapular artery, branch of the transverse cervical artery is in the field of neck dissection, and although it can be preserved without compromising oncological results, there is a risk of damaging it. It also requires changing the position of the patient from dorsal to lateral decubitus at the end of the resection time..$^{8,9}$ The pectoralis major flap is simple to dissect, its pedicle is outside the field of neck dissection and previous radiant treatment if it existed. It allows large defects to be reconstructed, and for the flap to reach the upper end of the defect without tension, it is sometimes necessary to extend it inferiorly with random irrigation, including the fascia of the rectus abdominis muscles together with the skin. ${ }^{10}$ Its disadvantages are the bulge of the pedicle in the neck, a larger incision and postoperative scar if a cervical neck dissection was not performed, and the cosmetic problem in women. We used it in two patients in whom a neck dissection was performed due to having positive nodes. The complications were minor (small dehiscences due to lower flap traction) and healed spontaneously. In some studies they prefer to use free flaps to do the reconstruction. Hanasono et al., ${ }^{11}$ prefer to do the reconstruction of large defects with free flaps and those of smaller size with regional flaps. The surgery time was 6.9 hours vs 11.2 hours when regional and free flaps were used respectively. The time of hospitalization in intensive care and the complete hospital stay was shorter with the use of regional flaps vs. free flaps $(0.4+-1$ vs $3.4+-6.5$ and $4.1+-3.3$ vs $8,6+-11$ respectively). The incidence of complications was the same with regional or free flaps, but they were higher at the donor site for free flaps ( 0 vs. $13.3 \%)$. 


\section{Reconstruction Algorithm of Skin Defects In The Temporo-Parotidregion}
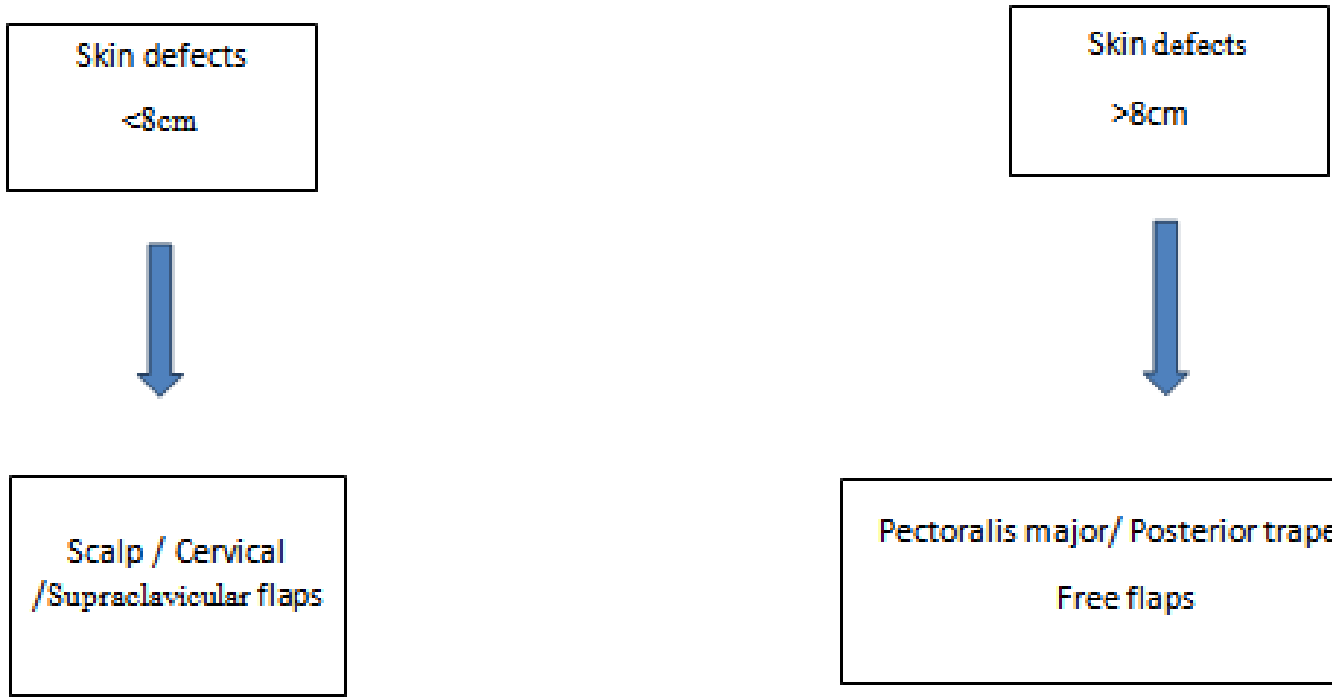

\section{DEFECTS $<8 \mathrm{~cm}$}

Radiation therapy history, Simultaneous neck dissection

Pectoralis Major / Free flap

\section{DEFECTS $>8 \mathrm{~cm}$ \\ Radiation therapy history, Simultaneous neck diss ection, High comorbidities, Lack of vess als for microanastomosis Pectoralis Major}

\section{Conclusion}

The results of the reconstructions with local and regional flaps of the skin defects caused by the resection of malignant tumors of the ear and the parotid gland were very good, since they allowed the repair of the defect with a good aesthetic result, without the need to perform grafts in the donor area and with few minor complications. All flaps were vital. In patients with advanced malignant tumors of the ear and parotid gland with infiltration of the surrounding skin, it is better to do the reconstruction with local or regional flaps due to the greater simplicity and speed of the surgical technique, similar aesthetic results and few complications.

\section{Acknowledgments}

None.

\section{Conflicts of interest}

The author declares that there is no conflict of interest to disclose.

\section{Funding}

None.

\section{References}

1. Wierzbicka M, Niemczyk K, Bruzgielewicz A, et al. Multicenter experiences in temporal bone cancer surgery based on 89 cases. Plos one. 2017;12(2):1-12.

2. Moncrieff MD, Hamilton SA, Lamberty GH, et al. Reconstructive options after temporal bone resection for squamous cell carcinoma. Journal of Plastic, Reconstructive \& Aesthetic Surgery. 2007;60(6):607-614.

3. Singh B, Cordeiro PG, Santamaría E, et al. Factors associated with complications in microvascular reconstruction of head and neck defects. Plast Reconstr Surg. 1999;103(2):403-411.

4. Serletti JM, Higgins JP, Moran S, et al. Factors associated with complications in microvascular reconstruction of head and neck defects. Plast Reconstr Surg. 2000;106(1):66-70. 
5. Moore MG, Lin DT, Mikulec AA, et al. The occipital flap for reconstruction after lateral temporal bone resection. Arch Otolaryngol Head and Neck Surg. 2008;134(6):587-591.

6. Miller C, Hanley J, Gernon T, et al. The submental island flap for reconstruction of temporal bone defects. Otology \& Neurotology. 2015,36:879-885.

7. Emerick KS, Herr MW, Lin DT, et al. Supraclavicular artery island flap for reconstruction of complex parotidectomy, lateral skull base, and total auriculectomy defects. JAMA Otolaryngol Head and Neck. 2014;140(9):861-866.

8. Demergasso F, Piazza M. Colgajo cutaneo aislado apediculo muscular en cirugía reconstructiva por cáncerde cabeza y cuello: tecnica original. The 47th CongresoArgentino de CirugiaForum de Investigaciones. Rev Argen Chir. 1977;32:27.
9. Urken ML, Naidu R, Lawson W, et al. The lowertrapezius is land musculocutaneous flap revisited. Report of 45 cases and a unifying concept of the vascularanatomy. Arch Otolaryngol Head Neck Surg. 1991;117:502.

10. Magee W, McCraw J, Horton C, et al. Pectoralis"paddle" myocutaneous flaps. The workhorse of head and neck reconstruction. Am J Surg. 1980;140(4):507.

11. Hanasono $\mathrm{MH}$, Silva $\mathrm{AK}, \mathrm{Yu} \mathrm{P}$, et al. Comprehensive management of temporal bone defects after oncologic resection. Laryngoscope. 2012;122(12):2663-2669. 